\title{
Effect of activation methods on the surface properties of carbonized biomass derived from fluted pumpkin stem (Telfairia occidentalis Hook F) waste
}

\author{
D. P. MARKMANUEL ${ }^{1}$, T. TARAWOU ${ }^{2 *}$, P. ADOWEI ${ }^{3}$ and M. Jnr HORSFALL ${ }^{3}$ \\ ${ }^{I}$ Department of Chemistry, Bayelsa State College of Education Okpoma Brass Island, Nigeria. \\ ${ }^{2}$ Department of Chemical Sciences, Niger Delta University, Wilberforce Island, \\ Bayelsa State, Nigeria. \\ ${ }^{3}$ Department of Pure and Industrial Chemistry, University of Port-Harcourt, \\ PMB 5323, Port-Harcourt, Nigeria. \\ "Corresponding author; E-mail: ttarawoufgc@yahoo.com; Tel: +234 (0) 8036726459
}

\begin{abstract}
The effect of chemical activation methods on some surface properties of carbonized biomass produced from fluted pumpkin waste was investigated using three activating reagents: $\mathrm{H}_{3} \mathrm{PO}_{4}, \mathrm{ZnCl}_{2}$ and $\mathrm{H}_{2} \mathrm{O}_{2}$. The surface properties studied were moisture content, sodium sorption capacity and iodine number. The surface properties of activated carbon were compared with that of the pure carbonized sample. The results obtained shows that the sample activated with $\mathrm{H}_{3} \mathrm{PO}_{4}(\mathrm{AM})$ with a sodium sorption capacity of $1.52 \mathrm{mmol} / \mathrm{g}$ was the most effective for the adsorption of sodium and other cations from solution, while the sample activated with $\mathrm{ZnCl}_{2}(\mathrm{BM})$ with sodium sorption capacity of $1.07 \mathrm{mmol} / \mathrm{g}$ has the least affinity for sodium. The iodine number determination also shows that the sample activated with $\mathrm{H}_{2} \mathrm{O}_{2}(\mathrm{NM})$ has the highest porosity with an iodine number of $60.3 \mathrm{mg} / \mathrm{g} \mathrm{I}_{2}$. This implies that chemically activated carbon produced from fluted pumpkin waste could be utilized as low-cost, economic and environment friendly biosorbents for the removal and recovery of metals and other cations in solution.
\end{abstract}

(c) 2013 International Formulae Group. All rights reserved.

Keywords: Activated carbon, activation methods, surface property, fluted pumpkin.

\section{INTRODUCTION}

Activated carbon has been widely used as adsorbents, catalyst/catalyst supports, electronic material and energy storage materials due to its high surface area and large pore volume. The specific surface area, pore structure and functional groups of activated carbon determine its applications (Figueiredo et al., 1999). The large pore structure and the high surface area of activated carbon could be controlled by various routes, such as, activation condition (activation agent, temperature and time), precursor etc, while the functional groups are mainly derived from 
activation process, precursor, heat treatment and chemical post treatment.

The functional groups found on the surface of activated carbon mainly contain oxygen, nitrogen, hydrogen, halogen etc. These heteroatoms bond (chemical activation) to the edges of the carbon layer and governs the surface chemistry of activated carbon (EL-Sayed and Bandosz, 2004). Among these heteroatoms, the oxygen containing functional groups (also known as surface oxides) are the widely recognized and the most common species formed on the surface of carbons, which significantly influence their performance in sensor (Lukaszewicz, 1999), energy storage and conversion system (Frackowiak and Beguin, 2001; Chen et al., 2004) and adsorption (Feron and Jansen, 1997; Li et al., 2002). The surface oxygen containing functional groups could be introduced by mechanical, chemical and electrochemical routes (Pittman et al., 1997; $\mathrm{Hu}$ and Wang, 2004). These modified surface oxides have been reported to enhance acidic property and improved the hydrophilic nature of activated carbon, which have been favourable for the adsorption of polar molecules.

While nitrogen containing groups could be introduced by ammine treatment, nitric acid treatment or some nitrogen containing molecule reacting with the precursor material especially nitrogen polymers (Carret et al., 2001). The nitrogen containing functional groups generally provide basic property, which enhances the attraction between activated carbon and acid molecule, such as dipole-dipole, H-bonding, covalent bonding and so on. In addition, halogen containing groups could be introduced through activated carbon reacting with halogen at moderate temperature; this modified activated carbon shows potential application in electrochemistry (Perez-Cadenas et al., 2003).
A modified activated carbon containing different functional groups has been used for technological applications such as extracting metallic cations from aqueous and nonaqueous solutions, in catalysis, for treatment of waste and toxic effluents produced by varieties of chemical processes. Based on the many applications of activated carbon, the need to modify as well as to characterize the surface functional groups of carbon materials is on the increase especially using agricultural by- products (wastes) as precursor material (Kadirvelu et al., 2000). Some of the agrowastes that have been successfully converted to activated carbons include coconut shell (Toles et al., 1999), cassava waste (Horsfall and Abia, 2003), pecan shell (Bansode et al., 2003), wild Cocoyam (Horsfall and Spiff, 2005a, 2005b), just to mention a few. As reported, simple chemical modifications have been shown to markedly enhance the metal ion binding capacity of agricultural by products (Bansode et al., 2003,). Moreso, the preparation of activated carbon from agricultural wastes has potential economic and environmental impacts. First, it converts unwanted low-value agricultural waste to useful, high-value adsorbents. Second, activated carbons are increasingly used in water to remove organic chemicals and metals of environmental and/or economic concern (Johns et al., 1998).

Fluted pumpkin stem waste has been used for activated carbon production because it is cheap and readily available. Literature research revealed that several tons of stem wastes are produced daily in market places and in homes all over Nigeria, but are scarcely useful. A single stem with leaves weighing 12 $\mathrm{kg}$ produces less than $200 \mathrm{~g}$ of leaves, leaving over $11 \mathrm{~kg}$ stem as waste and therefore create an environmental nuisance (Horsfall and Spiff, 2005b). Therefore, the purpose of this study is to investigate the effect of chemical 
activation methods on the surface properties of carbonized biomass of fluted pumpkin (Telfairia occidentalis Hook F) stem waste.

\section{Abbreviations}

AM --Acid Modified, $\mathrm{H}_{3} \mathrm{PO}_{4}$

- $\quad$ BM---Base Modified, $\mathrm{ZnCl}_{2}$

- NM--Neutral Reagent Modified, $\mathrm{H}_{2} \mathrm{O}_{2}$

- PC---Pure Carbonized Fluted Pumpkin Waste Biomass

\section{MATERIALS AND METHODS}

\section{Adsorbent}

The adsorbent used for this work is the stem waste of fluted pumpkin (Telfairia occidentalis Hook $F$ ) obtained from a local market at Agudama - Epie in Yenagoa Local Government Area of Bayelsa State, Nigeria. The fluted pumpkin wastes were washed with distilled water, sun-dried, cut into pieces, dried in an oven for 2 days at a temperature of 80-100 ${ }^{\circ} \mathrm{C}$ to a constant weight and carbonized at an optimum temperature of 550 ${ }^{\circ} \mathrm{C}$ for two hours. The carbonized sample was ground into a fine powder using mortar and pestle. This powder was divided into 2 portions. The first portion was left as pure carbonized fluted pumpkin waste (PC) while the second portion of the powder was taken for activation.

\section{Activation of sample}

The activating reagents employed for this work were:

- Orthophosphoric Acid, $\mathrm{H}_{3} \mathrm{PO}_{4}$

- Zinc Chloride, $\mathrm{ZnCl}_{2}$

- Hydrogen Peroxide, $\mathrm{H}_{2} \mathrm{O}_{2}$

$25.00 \pm 0.01 \mathrm{~g}$ each of carbonized sample was weighed and transferred into three different beakers containing $500 \mathrm{ml}$ of $0.05 \mathrm{M} \mathrm{H}_{3} \mathrm{PO}_{4}$, $\mathrm{ZnCl}_{2}$ and $\mathrm{H}_{2} \mathrm{O}_{2}$ respectively. The content of each beaker was thoroughly mixed and heated on a hot plate until it formed a paste and then pyrolysed at $500{ }^{\circ} \mathrm{C}$ for two hours. After cooling, it was washed with distilled water to a constant $\mathrm{pH}$ and dried at $100{ }^{\circ} \mathrm{C}$ for three hours. Thus, four different adsorbents were produced.

- Fluted pumpkin waste activated with Orthophosphoric acid, $\mathrm{H}_{3} \mathrm{PO}_{4}$

- Fluted pumpkin waste activated with Zinc chloride, $\mathrm{ZnCl}_{2}$.

- Fluted pumpkin wasted activated with Hydrogen peroxide, $\mathrm{H}_{2} \mathrm{O}_{2}$.

- The pure carbonized fluted pumpkin waste (PC).

\section{Determination of moisture content}

The standard test method for moisture in activated carbon as in ASTM D2867-99 was used. A crucible was dried, cooled in desiccators and weighed. The activated carbon sample was then thinly spread in the crucible and weighed. The crucible was then heated in an air circulation oven at $106{ }^{\circ} \mathrm{C}$ to constant weight. The moisture content was calculated using the equation 1 .

$$
\text { MoistureContent }(\%)=\frac{\text { Loss in weight on drying } \mathrm{x} 100}{\text { Initial sample weight }(\mathrm{g})}
$$

\section{Determination of sodium sorption capacity}

Sodium sorption capacity was determined in order to compare the total sorption capacity of the activated and pure carbonized carbons for cations. This was achieved by contacting $200 \mathrm{mg}(0.2 \mathrm{~g})$ of each sorbent with $25 \mathrm{ml}$ of $0.1 \mathrm{M} \mathrm{NaOH}$ and the resultant mixture was allowed to equilibrate on a mechanical shaker for 72 hours. Each mixture was then filtered to remove the adsorbent and the filtrate of each mixture was back titrated with $0.1 \mathrm{M} \mathrm{HCl}$.

\section{Determination of iodine number}

One gram $(1.0 \mathrm{~g})$ of absorbent was weighed into a sample bottle and $30 \mathrm{ml}$ of 0.1 M $\mathrm{I}_{2}$ solution was added and the mixture shaken in a mechanical shaker for one hour. 
After shaking, the mixture was filtered into a conical flask and titrated against $0.1 \mathrm{M}$ $\mathrm{Na}_{2} \mathrm{~S}_{2} \mathrm{O}_{3} .5 \mathrm{H}_{2} \mathrm{O}$.

\section{RESULTS AND DISCUSSION}

\section{Moisture content}

The moisture content of the fluted pumpkin stem waste biomass was found to be $68.26 \%$. While the moisture content of the pure carbonized and modified samples are presented in Table 1.

\section{Sodium sorption capacity}

The sodium sorption capacities for the various samples of the carbon are presented in Table 2. The sodium sorption capacity for the various samples of carbon was determined to find out the affinity of the various samples of fluted pumpkin waste biomass (activated and pure carbonized) for sodium compounds in aqueous solution.

\section{Iodine number}

The iodine number of the carbon samples is presented in Table 3.

Table 1: Moisture content of pure and activated carbon samples.

\begin{tabular}{lc}
\hline Sample & Moisture content $(\%)$ \\
\hline AM & $16.35 \pm 0.22$ \\
BM & $17.23 \pm 0.15$ \\
NM & $19.03 \pm 0.05$ \\
PC & $21.33 \pm 0.32$ \\
\hline
\end{tabular}

Table 2: Sodium sorption capacity of activated and pure carbonized samples of fluted pumpkin waste biomass.

\begin{tabular}{lcc}
\hline Sample & \multicolumn{2}{c}{ Sodium sorption capacity $(\mathbf{m m o l} / \mathbf{g})$} \\
\cline { 2 - 3 } & Range & Mean \pm Std \\
\hline AM & $1.45-1.55$ & $(1.52 \pm 0.047)$ \\
BM & $1.05-1.10$ & $(1.07 \pm 0.024)$ \\
NM & $1.30-1.35$ & $(1.32 \pm 0.024)$ \\
PC & $1.40-1.55$ & $(1.47 \pm 0.071)$ \\
\hline
\end{tabular}

Table 3: Iodine number of activated and pure carbonized samples of fluted pumpkin waste biomass.

\begin{tabular}{lc}
\hline Sample & Iodine number $\left(\mathbf{m g} / \mathbf{g} \mathbf{~ I}_{2}\right)$ \\
\hline AM & 54.3 \\
NM & 60.3 \\
BM & 59.3 \\
PC & 55.3 \\
\hline
\end{tabular}


The moisture content indicates that the volatile materials present in the fluted pumpkin were removed during carbonization. The analyses (Table 1) showed a low amount of moisture, indicating that the particle density is relatively small and that the carbon should be an excellent material for use in column or fixed bed reactors. The moisture contents of the carbon samples are comparable to other materials used for batch analysis (Ekpete et al., 2010; Tarawou et al., 2010).

As indicated in Table 2, the sodium sorption capacity for the various samples were in the range; AM 1.45-1.55 $\mathrm{mmol} / \mathrm{g}$ $(1.52 \pm 0.047)$, BM $1.05-1.10 \mathrm{mmol} / \mathrm{g}(1.07$ $\pm 0.024), \mathrm{NM} 1.30-1.35 \mathrm{mmol} / \mathrm{g}(1.32 \pm$ 0.024), PC 1.40-1.55 mmol/g (1.47 \pm 0.071$)$ respectively. Hence, the Sodium Sorption Capacity of the fluted pumpkin waste biomass follows the order; AM (1.52 $\mathrm{mmol} / \mathrm{g})>\mathrm{PC}(1.47 \mathrm{mmol} / \mathrm{g})>\mathrm{NM}(1.32$ $\mathrm{mmol} / \mathrm{g})>\mathrm{BM}(1.07 \mathrm{mmol} / \mathrm{g})$. The result shows that AM being the most acidic among the samples had the highest sorption capacity for sodium and its compounds, while BM has the least affinity for sodium and its compounds. Thus, this result indicates that acid modified carbon could be a suitable adsorbent for the sorption of sodium and other cations from aqueous solution. Acid treated carbon generally oxidizes the activated carbon surface, it enhances acidic property, removes mineral elements and improves the hydrophilic nature of the carbon surface, thus causing an increase in the total number of surface oxygen containing functional groups (Figueiredo et al., 1999). The results of this study are similar to those of other researchers (Mostafa, 1997; Moreno et al., 1997).
The iodine number measures the porosity of a material by adsorption of iodine from a solution on it. A sample with a higher iodine number is of higher porosity. Table 3 shows that the iodine number in $\mathrm{mg} / \mathrm{g}$ follows the order: NM $(60.3 \mathrm{mg} / \mathrm{g})>\mathrm{BM}(59.3 \mathrm{mg} / \mathrm{g})>\mathrm{PC}$ (55.3 mg/g) > Am (54.3 mg/g). Thus, the results obtained from this work indicate that, $\mathrm{NM}$ with highest Iodine Number $(60.3 \mathrm{mg} / \mathrm{g})$ is of the highest porosity among the various samples of the fluted pumpkin waste. This implies that, Neutral Modified (NM) activated carbon will be a good adsorbent where a high micropore content of the adsorbate is needed for adsorption to occur.

\section{Conclusion}

Fluted pumpkin (Telfairia occidentalis Hook $F$ ) stem waste has, all the while, been regarded as waste, thus creating environmental nuisance; but this study has shown that the stem wastes of fluted pumpkin can be processed into activated carbon and utilized as low-cost, economic and environmental friendly adsorbents for the removal of toxic and recovery of valuable metals from solutions and industrial wastewater. Thus, producing activated carbon from fluted pumpkin will help to reduce it as a waste in the environment as well as providing an affordable technology for the manufacture of activated carbon for small and medium-scale industries in Nigeria. Furthermore, the experimental results show that chemical activated samples (e.g. $\mathrm{H}_{3} \mathrm{PO}_{4}$ ) of the fluted pumpkin waste biomass would be more effective for the adsorption of sodium and other cations from aqueous solution than the pure carbonized fluted pumpkin waste biomass. NM has the highest iodine number and hence most porous of the carbon samples. BM has the lowest sodium sorption capacity and therefore 
has the least affinity for sodium and its compounds.

\section{ACKNOWLEDGEMENTS}

The authors gratefully acknowledged the kind permission of the Department of Pure and Industrial Chemistry, University of Port-Harcourt and Mr. T. Peter for the use of reagents and Facilities in their Laboratory.

\section{REFERENCES}

Bansode RR, Losso JN, Marshall WE, Roa RM, Portiere JR 2003. Adsorption of metal ion by pecan shell based GACS. Biores. Technol., 89: 115-119.

Carret PJM, Nabais JMV, Ribeiro-carrot MML, Pajares JA. 2001. Preparation of activated carbon fibers from acrylic textile fibers. Carbon, 39: 1543 - 1555.

Chen X, Zhang Y, Goa XP, Pan GL, Jiang $\mathrm{XY}$, Qu JQ. 2004. Electrochemical hydrogen storage of carbon nontubes and carbon nonfibers. Int. J. Hydrogen Energy, 29: 743 - 748.

Ekpete OA, Horsfall M jnr, Tarawou T. 2010. Potential of fluted and Commercial Activated Carbons for Phenol removal in Aqueous Systems. ARPN J. Eng. Appl. Sci., 5: 1-9.

EL-Sayed Y, Bandosz TJ 2004. Adsorption of Valeric acid from aqueous solution onto activated carbons: Role of Surface Basic Sites. J. Colloid Interface, 273: 64-72.

Feron PHM, Jansen AE. 1997. The production of carbon dioxide from flue gas by membrane gas adsorption. Energy Converts Manage, 38: 593 598.

Figueiredo JL, Pereira MFR, Freitas MMA, Orfao JJM. 1999. Modification of the
Surface Chemistry of Activated Carbon. Carbon, 37: 1379 - 1389.

Frackowiak E, Beguin F. 2001. Carbon materials for the electrochemical storage of energy in capacitors. Carbon, 39: 937 950.

Horsfall MJnr, Abia AA. 2003. Sorption of cadmium (II) and zinc (II) ions from aqueous solution by cassava waste biomass (Manihot Sculenta). Water Res., 37: 3913 4923.

Horsfall MJnr, Spiff AI. 2005a. Kinetic studies on the sorption of lead and cadmium ions from aqueous solution by caladium bicolor (wild cocoyam) biomass. Bull. Chem. Soc. Ethiop., 19, 89-95.

Horsfall MJnr, Spiff AI. 2005b. Equilibrium sorption Study of $\mathrm{Al}^{3+}, \mathrm{CO}^{2+}$ and $\mathrm{Ag}^{+}$in aqueous solutions by fluted pumpkin (Telfairia occidentalis Hook f) Waste Biomass. Acta Chimi Slov., 52: 174-181.

Hu CC, Wang CC. 2004. Effects of electrolytes and electrochemical pretreatments on the capacitive characteristics of activated carbon fabrics for Super capacitors. $J$. Power Source, 125: 299 - 308.

Johns MM, Marshall WE, Toles CA. 1998. The effect of activation method on the properties of pecan shell activated carbon. J. Chem. Technol. Biotechnol., 74: 1037-1044.

Kadirvelu K, Pakenival M, Kalpans R, Rajes, WS. 2000. Activated carbon from agricultural by-product for the treatment of dyeing industrial wastewater. Biores. Technol., 74: 263 - 265.

Li YH, Lee CW, Gullet BK. 2002. The effect of activated carbon surface moisture on how temperature mercury adsorption. Carbon, 40: $65-72$.

Lukaszewicz JP. 1999. Carbon - film - based humidity sensor containing sodium or 
potassium Recovery Effect. Sens. Actuators B. Chem., 60: 184 - 190.

Moreno-Castilla C, Carrasco-Marin F, Maldonado-Hoder FJ, Rivera-Utrilla J. 1997. Effects of non-oxidant and oxidant acid treatment on the surface properties of an activated carbon with very low ash content. Carbon, 36: 145 151.

Mostafa MR. 1997. Adsorption of mercury, lead and cadmium ions on modified activated carbon. Adsorption Sci. Technol., 15: 551 - 557.

Perez-Cadenas AF, Maldonado-Hodar FJ, Moreno-Castilla C. 2003. On the nature of surface acid sites of chlorinated activated carbons. Carbon, 41: 473 - 478. Pittman JrCu, He GR, Wa B, Gardner SD. 1997. Chemical modification of carbon fiber surface by nitric acid oxidation followed by reaction with tetraethylenepentamine. Carbon, 35: 317 331.

Tarawou T, Wankasi D, Horsfall MJnr. 2010. Sorption kinetic study on the removal of Basic Blue -9 dye using activated carbon produced from water spinach. Int. J. Biol. Chem. Sci., 4: 703-709.

Toles CA, Marshall WE, Johns MM. 1999.

Surface functional groups on acid activated nutshell carbons. Carbon, 37: 1207 - 1214. 